\title{
Absence of Pectoralis Major
}

\author{
Dr. K. Sushma, Dr. D. Asha Latha, Dr. M. Sri Hari Babu Dr. A. Vasanthi, \\ Dr. S. Suneetha \\ Department of Anatomy/ Andhra Medical college, Visakhapatnam.
}

\begin{abstract}
During routine dissection in the Department of Anatomy, Andhra Medical College, we have found the absence of Pectoralis major on one side i.e., left side. The Pectoralis major and minor of right side are well developed. The clavicular fibres of left Pectoralis major are well developed. whereas the sternocostal fibres were absent. The Pectoralis minor on that side was thinned out. The relative literature of such an anatomical variant is discussed during the presentation.
\end{abstract}

Key Words: Pectoralis major, Sternocostal fibres, clavicular fibres.

\section{Introduction}

Partial or complete absence of Pectoralis Major is the most common muscle anomaly. Bing estimated that they comprise $28 \%$ of cases of congenital absence of muscles. Description of this anomaly is usually restricted to reports of Poland's syndrome, but may also be an isolated finding. Poland's syndrome consists of partial or complete absence of Pectoralis major and ipsilateral upper limb anomaly synbrachydactyly.

\section{Case report:}

In routine dissection in our department we have observed a case of absence of pectoralis major on left side. The sternocostal fibres were absent. The clavicular fibres were present. The right side pectoralis major appeared normal. Left pectoralis minor was thinned out. Left deltoid was observed to be hypertrophied. Teres major was normal. No rib deformities were detected.

Table 1

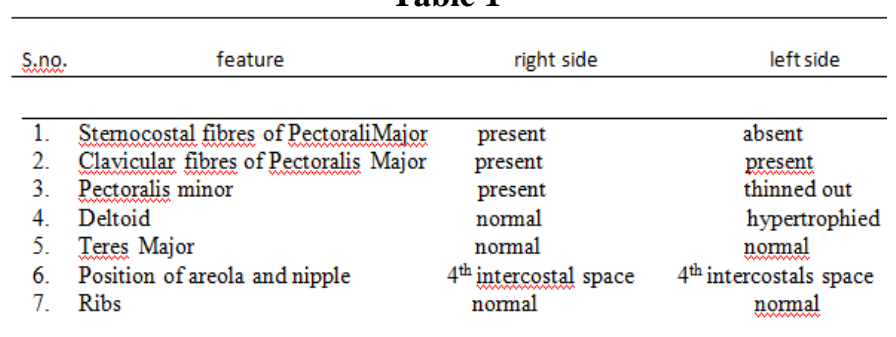
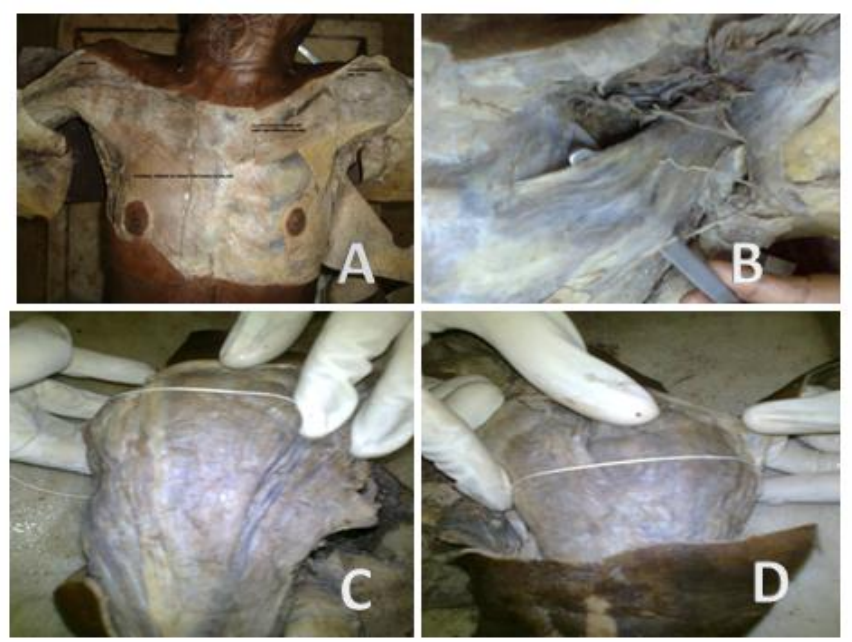

Figure 1: Absence of Pectoralis major on the left side. A - left side sternocostal fibres are absent. Left clavicular fibres are present. Right side sternocostal and clavicular fibres are present. B - Left pectoralis minor appears thinned out. C - Right side Deltoid muscle D - Left side Hypertrophied Deltoid. 


\section{Results And Discussion:}

The Pectoralis major has two origins, the sternocostal head and the clavicular head. Both fleshy heads bend to form a tendon which turns on itself and insert into the lateral wall of bicipital groove of humerus. It is supplied by the thoraco-acromial branch of the axillary artery.

The developmental changes in the pectoral muscle mass occurring at different sizes of the embryo are listed below.

Table 2:

\begin{tabular}{cl} 
Size of the embryo (CRL) & developmental change \\
\hline $\begin{array}{l}9 \mathrm{~mm} \\
11 \mathrm{~mm}\end{array}$ & $\begin{array}{l}\text { the pectoral muscle mass is largely above the first rib } \\
\text { it extends lower but it is still undifferentiated into its component } \\
\text { parts and is not attached to the ribs or humerus }\end{array}$ \\
$16 \mathrm{~mm}$ & $\begin{array}{l}\text { the clavicular portion is split off and the remainder then divides } \\
\text { into the stermal portion and pectoralis minor. }\end{array}$ \\
\hline
\end{tabular}

Perhaps the failure of the primitive mass to attach itself to the ribs and the sternum might allow its nondifferentiation into its normal component parts. This coincides with the known fact that the defects are usually in the caudal portion. Goldberg and Mazzei postulated the theory of nerve root dysgenesis and postulated a concept of local injury occurring in the $6-7$ week old embryo, at a time when the immature hand is juxtapositioned next to the differentiating pectoralis major muscle mass. It may be attributed to a vascular injury which compromises the circulation in the region, during limb bud formation. Chest wall deformities like Pectus excavatum and pectus carinatum may occur secondarily by unbalanced muscular action due to missing pectoralis major on the involved side. Adolescent females present to the clinic with hypoplastic breast for implants. Absence of Pectoralis minor and sternocostal fibres of Pectoralis major is the most innocuous cause of unilateral hyperluscent lung. Poland's syndrome is a contraindication for pectoral myofascial flap used for head and neck reconstructive surgery. Anomalies associated with Congenital absence of Pectoralis major include ipsilateral digital anomalies and upper limb shortening, absence or hypoplasia of the breast, defective ribs and costal cartilages, deficiency of chest and axillary hair and sweat glands and scoliosis.

To conclude there are no other anomalies detected in this case, hence the absence of pectoralis major in this case could be an embryological defect.

\section{References}

[1] CLARKE : Congenital variation of Pectoral muscles J. Anat Physiol. 49:155-164, 1915

[2] Poland A : Deficiency of Pectoral muscle. Grey’s Hosp Rep 6:191-193, 1841

[3] Katz I, Fischer RM, Berardinelli SD: Congenital absence of the Pectoral muscle. The Am J of Roentgenol 76:599-604, Sep 1956.

[4] Stein HL: Roentgen diagnosis of congenital absence of Pectoralis muscle, Radiology 83:63-66, 1964

[5] Pers: Aplasia of the anterior thoracic wall, the pectoral muscles, and the breast. Scand J Plast Reconstr Surg 2 : 125-138, 1968

[6] Ehrenhaft JL, Rosi NP, Lawrence MS: Developmental chestwall defects. Ann Thoracic Surg 2:384-398, May 1966

[7] Lewis WH : Development of the arm in man. Am J Anat 1:145-185, 1901. 